\title{
The Unity of a Tractarian Fact
}

\begin{abstract}
It is not immediately clear from Wittgenstein's Tractatus how to connect his idea there of an object with the logical ontologies of Frege and Russell. Toward clarification on this matter, this paper compares Russell's and Wittgenstein's versions of the thesis of an atomic fact that it is a complex composition. The claim arrived at is that whilst Russell (at times at least) has one particular of the elements of a fact - the relation responsible for the unity of the whole, for Wittgenstein the unity of a fact is the product of copulative powers inherent in all its elements. All kinds of constituents of Tractarian facts - all kinds (forms) of object - are, to use Fregean terminology, unsaturated.
\end{abstract}

The object of investigation of this paper is the nature of the composition, in Wittgenstein's Tractatus, of an atomic fact from its constituent objects. To this, our approach will be through the work of Wittgenstein's early mentor, Russell, from whom the idea of facts as complexes of objects was inherited. ${ }^{1}$ Pleasingly, we shall find that light is cast by our results on the claim of Tractatus 1.1 that 'The world is the totality of facts, not of things'. In this light will become visible a failing in a certain common understanding of that pronouncement.

\section{Russell on the unity of a complex}

Occurring in Russell's universe, from 1903 through to 1918 and beyond, are simples and also complexes, a complex being not simple in that it has parts (constituents):

We will give the name of "a complex" to any such object as " $a$ in the relation $R$ to $b$ " or " $a$ having the quality $q$ " or " $a$ and $b$ and $c$ standing in the relation $S$." Broadly speaking, a complex is anything which occurs in the universe and is not simple. (PM p44)

A “complex" is anything analysable, anything which has constituents. (TK p79)

If we take some particular dual complex $x R y$, this has three constituents, $x, R$, and $y$. (TK p114)

For example, “A differs from B” or “A's difference from B,” is a complex of which the parts are $\mathrm{A}$ and $\mathrm{B}$ and difference. (POM p139)

The parts of a complex are not, however, all parts of the same kind. Russell has a theory of the constitution of complexes under which not all components of a complex figure there in the same manner. This is as follows: An entity may figure in a complex either as a term or as a relation; in any (atomic) complex, one entity appears as a relation and all the others as terms; if there are $n$ entities appearing as terms in a complex, then the entity appearing as relation appears there as an n-ary relation. And this theory yields for Russell the following fundamental logical kinds of entities: term, an entity which may feature as a term in a complex, and $n$-ary relation, an entity which may feature as an n-ary relation in a complex. A unary relation we call a predicate; relations of all orders we call universals; terms which are not universals we call particulars.

In any complex, there are at least two kinds of constituents, namely the terms related, and the relation which unites them. ... In (say) “A precedes B”, A and B occur differently from the way in which "precedes” occurs. ... An entity which can occur in a complex as "precedes" occurs in "A precedes B" will be called a relation. When it does occur in this way in a complex, it will be called a "relating relation" in that complex....

Atomic complexes may be classified according to the number of terms other than the relating relation that they contain; we will call them dual complexes if they contain two terms, and so on. Relations may be similarly classified: relations which can be relating in dual complexes will be called dual relations, and so on....

It may be that there are complexes in which there is only one term and one predicate, where the predicate occurs as relations occur in other complexes. In that 
case, predicates will be defined as entities occurring in this manner in complexes containing only one other entity....

Relations and predicates together will be called "universals". All the constituents of a complex are either particular or universal, and at least one must be universal. (TK pp.80-81)

A particular is defined as an entity which can only enter into complexes as the subject of a predicate or as one of the terms of a relation, never as itself a predicate or a relation. (TK pp. 55-56)

So an atomic complex is composed of $n$ terms and an n-ary relation - those are its constituents. But how, we need now to be told, are they constituents? What is this composition of theirs? Or to put the inquiry in alternative terms: a complex is to have a unity beyond the mere set of its elements - in what does this unity consist? This basic question exercised Russell greatly throughout his work in logic. I shall argue that over the period 1903-1918 three distinct responses are offered, which will be referred to below as that of an early, a middle and a late Russell.

First up we find:

Owing to the way in which the verb [the relation] actually relates the terms of a proposition [a complex], every proposition has a unity which renders it distinct from the sum of its constituents. (POM p52)

'A's hatred for B', for example, is a complex in which hatred combines A and B into one whole. (RUP p108)

Whenever a relation holds between two or more terms, it unites the terms into a complex whole. (PP p74)

The suggestion of the early Russell, then, is that a complex's unity is effected by its relation. In a complex the relation actually relates the terms, and in so doing unites them together with itself into a whole. The relation, we might say, is as cement to the terms' bricks (PP p74). Stating this idea, however, we must take a little care, for Russell also holds that there may in fact be more than one relation occurring in an atomic complex. That is to say: relations may appear in complexes not just as relations but also as terms; just as do particulars, universals may stand as terms in relation to each other. $^{2}$ More carefully put, then, the suggestion is that it is the entity appearing as relation that effects the complex's unity. Unfortunately for Russell, however, his theory that universals are terms too is going to render this response problematic. To see how we need first to note that these two guises of universals (as term and as relation) are not both equally guises.

In the Principles of Mathematics Russell writes:

The twofold nature of the verb, as actual verb and as verbal noun, may be expressed, if all verbs are held to be relations, as the difference between a relation in itself and a relation actually relating. (POM p49, my italics)

And Russell says that he "will use synonymous with [the word term] the words unit, individual, and entity” (POM p43). An entity occurring as a term of a complex, we should recognise, is occurring there in and of itself; to occur as a term in a complex is to occur in the world as a self-standing unit. An entity occurring as the relation in a complex, by contrast, is not standing there inertly by itself: it is occurring there as, essentially, a part of that complex - it is there going between, actually relating, the complex's terms. The bricks and cement metaphor is thus particularly apt: the terms, the bricks, stand there as independent units, but there is in the world no cement, no entity occurring as relation, without bricks there cemented together. And this contrast between the two modes of occurrence in a complex is, we should see, essential to the idea that it is the relation and not the terms which unify the complex. If the occurrence of the relation were, as that of the terms, one of an entity standing on its own, then the complex would consist only of a variety of independently self-standing entities - it would, that is to say, amount to nothing more than the mere collection of those entities. 
Still, difficulty arises for Russell with the unity of complexes from the fact that whilst the occurrence of an entity as a relation is an occurrence essentially within a complex, nonetheless the relation there occurring is in itself a term existing in the world independently of any complex. What we have with Russell here is the idea that a relation is a brick doing duty as cement between other bricks. And this proves problematic for if the constituents of a complex are, in themselves, all bricks, then what we get if we analyse that complex into its individual constituents is, precisely, a series of bricks. A series of bricks, however, does not make for a wall: for a wall we need cement:

Consider, for example, the proposition “A differs from B.” The constituents of this proposition, if we analyze it, appear to be only A, difference, B. Yet these constituents, thus placed side by side, do not reconstitute the proposition. The difference which occurs in the proposition actually relates $\mathrm{A}$ and $\mathrm{B}$, whereas the difference after analysis is a notion which has no connection with A and B. (POM p49)

A proposition has a certain indefinable unity, in virtue of which it is an assertion; and this is so completely lost by analysis that no enumeration of constituents will restore it, even though itself be mentioned as a constituent. There is, it must be confessed, a grave logical difficulty in this fact, for it is difficult not to believe that a whole must be constituted by its constituents. (POM pp466-467)

If we break up a complex into its elements, then we are left, the problem is, with entities which do not fit back together to form the complex. We thus seem to be forced into saying that the complex's constituents are after all insufficient (inappropriate) in themselves for a unity as opposed to a mere set as they include no cement, no unifying element. ${ }^{3}$

In response to this “grave logical difficulty”, Russell - the 'middle Russell' now - moves to suggest that the unity of a complex is effected not by any of its elements but rather by something else - by a logical form. The whole is not, after all, constituted by its constituents. As early as 1904, Russell had considered the suggestion that a complex is "a unity formed by certain constituents combined in a certain manner" (OF p98), where "the mode of combination of the constituents of a complex is not itself one of the constituents of the complex" (OF p98). By 1913, this 'mode of combination' is being called the 'form', and in place of the assertion that the complex aRb consists of a and b united in relation $\mathrm{R}$, we find: " $\mathrm{aRb}$ consists of $\mathrm{a}$ and $\mathrm{R}$ and $\mathrm{b}$ united in the general form of a dual complex" (TK p128). What, though, is this 'form'?

Well, it is insisted throughout that a complex's form is not itself a constituent of that complex:

It is obvious, in fact, that when all the constituents of a complex have been enumerated, there remains something which may be called the "form" of the complex, which is the way in which the constituents are combined in the complex. (TK p98)

More positively, we are told:

For example, the form of all subject-predicate complexes will be the fact that "something has some predicate"; the form of all dual complexes will be "something has some relation to something”. (TK p114)

So the complex 'aRb' is analysed now into its constituents $a, \mathrm{R}$, and $\mathrm{b}$, and its form $(\exists \mathrm{x}, \Lambda, \mathrm{y})$ (x stands in $\Lambda$ to y). But still, what is this form? It is, we are told, a constituentless fact (TK p114), but is it then, say, a term? Well, Russell is keen to assert that it is "not a "thing”" (TK p98), preferring to call it "a structure” (TK p114). He does, however, also call it a "logical object” (TK p99). Frank as ever, Russell admits that "it is not at all clear what is the right account of "form”" (TK p99). The point to note here is that he is under great pressure to admit forms as terms, pressure stemming from within his theory of judgment, and also from a general argument to the effect that everything must be a term. ${ }^{4}$ But if that is done - which it is - the difficulty faced by the early Russell would seem to remain unmet: the form of a complex will be a self-subsistent entity just as the constituents, and so the results of an analysis of a complex will again be a series of entities standing there individually, inappropriate for a unity beyond their mere sum. 
In a letter of January 1913 Wittgenstein makes an alternative criticism of this middle Russellian theory. ${ }^{5}$ The letter is of interest to us more by virtue of the alternative Wittgenstein offers than by the criticism itself:

I have changed my views on "atomic" complexes: I now think that qualities, relations (like love) etc. are all copulae! That means I for instance analyse a subjectpredicate proposition, say "Socrates is human" into "Socrates" and "something is human”, (which I think is not complex). The reason for this is a very fundamental one: I think that there cannot be different Types of things! In other words whatever can be symbolised by a simple proper name must belong to one type. And further: every theory of types must be rendered superfluous by a proper theory of the symbolism: For instance if I analyse the proposition Socrates is mortal into Socrates, mortality and $(\exists x, y) \in_{1}(\mathrm{x}, \mathrm{y})$ I want a theory of types to tell me that "mortality is Socrates" is nonsensical, to prevent me making the substitution the wrong way round. But if I analyse (as I do now) into Socrates and ( $\exists \mathrm{x}) . \mathrm{x}$ is mortal or generally into $\mathrm{x}$ and $(\exists x) . \varphi x^{*}$ it becomes impossible to substitute the wrong way round because the two symbols are now of a different kind themselves.

* Props which I formerly wrote $\epsilon_{2}(\mathrm{a}, \mathrm{R}, \mathrm{b})$ I now write R(a, b) and analyse them into a, b, and $(\exists x, y) R(x, y)$ [which last is] not complex. (CL pp. 24-25)

Ignoring the theory of types/theory of symbolism ideas, we can note that Wittgenstein is advocating a position in which Russell's copulating form is subsumed into his (at that time) non-copulating relation to make a copulating relation constituent. Now this might seem merely to return us back to where we were before the idea of form was introduced, to the early Russell, but let's note that the constituent $\mathrm{R}$ of that early theory has now been replaced by $(\exists x, y) R(x, y)$. What importance has this? Well, recall that the central purpose of the logical form was to act as copula, that copulation was to be essential to it the logical form of a complex was to be, precisely, the mode of combination of the constituents. What Wittgenstein is suggesting, then, by writing $(\exists x, y) R(x, y)$ rather than $R$ as the third constituent of the complex is that what we have here is a constituent which is essentially copulating - a constituent which is not a term, a constituent which does not stand on its own. Relations, he says, are copulae.

Wittgenstein is thus mooting the possibility that there are things (constituents of complexes) which are not terms, but rather are essentially copulative.

This suggestion goes directly against an earlier argument (and indeed earlier sentiment) of Russell's that everything must be a term, must be capable of being made the subject of a proposition. ${ }^{6}$ Nevertheless it is something which Russell comes to embrace. In his 1918 lectures The Philosophy of Logical Atomism, Russell - the 'late Russell', now - declares that “a relation can never occur except as a relation, never as a subject” (PLA p206), and he (re)defines particulars with

Particulars $=$ terms of relations in atomic facts. Df. (PLA p199)

More, it is asserted:

Particulars have this peculiarity, among the sort of objects that you have to take account of in an inventory of the world, that each of them stands entirely alone and is completely self-subsistent. It has that sort of self-subsistence that used to belong to substance, except that it usually only persists through a very short time, so far as our experience goes. That is to say, each particular that there is in the world does not in any way logically depend upon any other particular. There is no reason why you should not have a universe consisting of one particular and nothing else. That is a peculiarity of particulars. In the same way, in order to understand a name for a particular, the only thing necessary is to be acquainted with that particular. (PLA p201)

With relations, by contrast, we have that:

Understanding a predicate is quite a different thing from understanding a name. ... To understand a name you must be acquainted with the particular of which it is a name, and you must know that it is the name of that particular. You do not, that is to 
say, have any suggestion of the form of a proposition, whereas in understanding a predicate you do. To understand 'red', for instance, is to understand what is meant by saying that a thing is red. ... Exactly the same applies to relations, and in fact all those things that are not particulars. Take, e.g., 'before' in ' $x$ is before $y$ ': you understand 'before' when you understand what that would mean if $\mathrm{x}$ and $\mathrm{y}$ were given. (PLA p205)

This, as I've said, is an important change of heart. Where before both universals and particulars were "possessed of all the properties commonly assigned to substances" (POM p44) - self-subsistence, logical independence, logical subjecthood - now this character is withheld from universals. And lining up with this worldly contrast are contrasts now also in knowledge of the world, in knowledge of language, and in language itself: Unlike particulars, universals are not any longer to be objects of a dual acquaintance relation - to know a universal is not to know what that entity is in and by itself: rather, to know a universal is to know what it is for that entity to be a constituent in a complex. Correspondingly, the understanding of a sign for a universal consists not, as does the understanding of a sign for a particular, in the recognition of its being the sign for something with which one is acquainted, but rather in the understanding of what is meant by expressions of (atomic) judgments in which that sign figures. And with these, we shall say that whilst the sign for a particular, Cassio, is a complete, self-standing name, 'Cassio', the sign for a universal, love, is (something more like) an open sentence ' $x$ loves $y$ '.

There are, of course, important issues concerning how to understand these various contrasts and their interconnections: their exploration is not however a task for this paper (though we shall pay a brief revisit below with Wittgenstein added into the equation). Rather, what we can (quickly) do is note that the difficulty faced above by Russell's previous positions is now solved thus: Analysis leaves us not with a series of self-standing entities, but with a number of such entities and also a non-self-standing copulator. Placing the constituents of the complex alongside each other, we find that the particulars immediately slot into the universal to form the unity required. Borrowing terminology from Frege, we could say that the late Russell's particulars are saturated, and his universals are unsaturated. ${ }^{7}$ Rather than dwelling any further on Russell, however, let's turn now to Wittgenstein and ask: how, in the Tractatus, is the unity of an atomic fact accounted for?

\section{Wittgenstein on the unity of a complex}

An atomic fact, we are told in the Tractatus, is a combination of objects (TLP 2.01), is composed of objects (TLP 4.2211), has objects as constituents (TLP 2.011). But what manner of combination/composition/constitution is this?

Well, adding the Wittgensteinian heritage of Russell's late position to the Tractarian idea that "objects make up the substance of the world” (TLP 2.021), the possibility of assimilating Tractarian objects to late Russellian particulars might be a first port of call. Objects, the thought will go, are combined together to form complexes by 'relations', such (perhaps) as 'love' or 'being next to' which are not themselves objects but rather are essentially copulative and so insubstantial. Awkwardness arises for this idea, however, with Wittgenstein's insistence at Tractatus 2.01 that an atomic fact is a combination of objects (plural) ${ }^{8}$ : we would seem forced, on the suggested interpretation, to see Wittgenstein as denying 'a priori' the possibility of subject-predicate propositions (propositions asserting the existence of a fact involving only one Russellian particular/Tractarian object). More, Wittgenstein writes:

In an atomic fact, objects stand in a determinate relation to one another.

The determinate way in which objects are connected in an atomic fact is the structure of the atomic fact. (TLP 2.031-2.032)

We might find it unhappy to say that the way in which objects a and b are connected in the atomic fact that $\mathrm{a}$ is next to $\mathrm{b}$ - the way two things are connected when one is next to the other - is the structure of that fact. An entirely different structure would have to be posited for the fact that a is touching $b$. The idea of a structure is, surely, the idea of something formal, something abstract; the relation of being next to, even if it is insubstantial, seems to be considerably more material, more concrete. 
Of course, these considerations are inconclusive, but let's for the moment see them as exerting pressure to move Wittgenstein back towards the middle Russell in which the 'way in which entities are connected in a fact' is some sort of logical copula, a 'logical form' - something Russell himself called "a structure" (TK p114). Here the interpretation might begin to look more plausible. The combination of objects to form atomic facts is an immediate, logical combination; the objects are combined together within a certain logical form. We start to stumble with this too, however, when it is asked: what, for Wittgenstein, is this logical copula 'in' an atomic complex beside its constituent objects? What is this copula, this logical form, which is not itself an object? And we stumble here not because Wittgenstein, as Russell before him, fails to provide an adequate answer, but because Wittgenstein fails even to consider the question.

If we think that Wittgenstein has unnameable copulae (formal or otherwise) responsible for the unity of atomic facts, then we need to show passages in the Tractatus in which such a theory is exposed. But there are no such passages. What we find, rather, is:

In the atomic fact objects hang one in another, like the links of a chain. (TLP 2.03)

In an atomic fact objects hang one in another, like the links of a chain. The objects of an atomic fact are not held together by some further copula: rather, they hold themselves together. They are not ball bearings held together with some glue, but links of a chain holding each other together. The idea that the unity 'a next to b' consists of objects a and b held together by the 'being next to' relation (which is not an object) has to be rejected, as does the theory that it consists of the objects a, being next to and $b$ held together by a logical copula (the general form of the dual complex, or whatever). Both of those suggestions have it that it is something other than the objects which is responsible for the unity of atomic facts. Wittgenstein's insistence, however, is that it is the objects themselves which are so responsible.

On reading a preliminary translation of his Tractatus by C. K. Ogden in which Ogden had rendered section 2.03 with "In the atomic fact objects hang one on another, like the links of a chain", Wittgenstein made the correction:

Here instead of "hang one on another" it should be "hang one in another" as the links of a chain do! The meaning is that there isn't anything third that connects the links but that the links themselves make connexion with one another. So if "in" in this place is English please put it there. If one would hang on the other they might also be glued together. (LO p23)

The objects are not glued together, they hang in each other: they themselves do the copulating. And what this means, of course, is that Tractarian objects are not self-standing units. Throughout the above work with Russell we were driven by the fact that what is self-standing cannot copulate, cannot be responsible for a unity beyond itself; what copulates, what is responsible for a unity beyond itself, cannot (there) be self-standing. Thus to say that the objects are themselves jointly responsible for the unity of the fact of which they are the constituents is to say that those objects do not appear in that fact as self-standing units. More, as Wittgenstein is not, as at times was Russell, involved in any kind of dual role theory, it follows that objects occur in the world only as parts of complexes - Tractarian objects are essentially copulative, dependent, incomplete, unsaturated.

A deeper understanding of this conclusion is afforded by proper consideration of the Tractatus' opening passage on objects:

2.011 It is essential to things that they should be possible constituents of atomic facts.

2.012 In logic nothing is accidental: if a thing can occur in an atomic fact, the possibility of the atomic fact must be written into the thing itself.

2.0121 It would seem to be a sort of accident, if it turned out that a situation would fit a thing that could already exist entirely on its own.

If things can occur in atomic facts, this possibility must be in them from the beginning.

(Nothing in the province of logic can be merely possible. Logic deals with every possibility and all possibilities are its facts.) 
Just as we are quite unable to imagine spatial objects outside space or temporal objects outside time, so too there is no object that we can imagine apart from the possibility of combining with others.

This is an important passage whose full weight is not always felt. We have here two contrasting ideas: that an object has an essential nature which fits it to be a constituent of atomic facts, and that an object's essential nature consists in its being a possible constituent of atomic facts. What Wittgenstein is doing is rejecting the former and endorsing the latter.

To see this, let's model the former: Instead of objects take two-dimensional shapes, and instead of atomic facts, take regular tessellations of the plane using finitely many (but at least two) shapes. Here we can say that it is of the essence of certain of our shapes that they can combine together to form a certain tessellation. What certain shapes are, suit them to combine with each other in those ways in which they can in fact fit together. Nonetheless, what a shape is does not consist in its possibilities for such combinations. As Wittgenstein puts it, it is "a sort of accident" that certain shapes can tessellate together; the possibility of tessellation that certain shapes have is a "mere possibility", one which can be "discovered later" (TLP 2.0123) as opposed to one "written into" what those shapes are "at the very beginning". We can imagine a shape - we can have it there in thought - independently of any notion of its tessellations (we may not even have come across the idea of such structures!).

All this Wittgenstein rejects of objects. The possibilities of an object to occur in facts are constitutive of, rather than resultant from, its essential nature. Those possibilities are no kind of accident about the object to be discovered later: rather, they are written into the object from the very beginning. Objects do not, this is to say, stand alone, independently, with natures which (happen to!) fit them to combine together; rather what an object is, in essence, is a possible part of facts. There is no actuality in which an object's possibilities for combination are grounded; an object is, essentially, incomplete.

To drive this matter still harder home, let's turn very quickly to the linguistic aspect. We saw above that to understand a sign for a late Russellian universal (something essentially unsaturated) was to understand, given the meanings of relevant other signs, what is said by (atomic) propositions in which it figures.

Understanding a predicate is quite a different thing from understanding a name. ... To understand a name you ... do not ... have any suggestion of the form of a proposition, whereas in understanding a predicate you do. ... Take, e.g., 'before' in ' $\mathrm{x}$ is before $\mathrm{y}$ ': you understand 'before' when you understand what that would mean if $\mathrm{x}$ and $\mathrm{y}$ were given. (PLA p205)

Going hand in hand with universals being essentially possible parts of facts is that the understanding of symbols for them involves suggestion of the form of the propositions in which that symbol occurs. Looking at the Tractatus, we can note first that names (symbols for objects) are expressions, and then that:

3.311 An expression presupposes the forms of all the propositions in which it can occur. It is the common characteristic mark of a class of propositions.

3.312 It is therefore presented by means of the general form of the propositions that it characterizes.

In fact, in this form the expression will be constant and everything else variable.

3.313 Thus an expression is presented by means of a variable whose values are the propositions that contain the expression.

A Tractarian expression for an object (a name), just as a late Russellian expression for a universal, presupposes the forms of propositions in which it can occur, and, just as a late Russellian sign for a universal, is presented by means of a variable whose values are precisely those propositions. To understand a Tractarian name is to understand what would be asserted by propositions in which it figures, and what this means, I want to suggest again, is that as late Russellian universals are incomplete, so too are the Tractarian objects.

So to repeat: Whilst the late Russell (under the influence of the pre-Tractarian Wittgenstein) had certain constituents of atomic facts (the universals) down as essentially incomplete, as logically 
dependent, as figuring in the world only as parts of complexes, the Tractarian Wittgenstein has all constituents of atomic facts, objects of all types (all forms), down in this way. And whilst the late Russell uses the incompleteness of his universals to account for the unity of facts, for Wittgenstein that unity is a product together of the incompleteness of all the fact-constituents - the objects all hang one in another. ${ }^{9,10}$

Finally for this section, we should notice and make good on a debt that this conclusion incurs: If the Tractarian objects are incomplete, what, then, is complete for the Tractatus? What, if not an object, is it that occurs in the Tractarian world as a self-standing unit? Well, Tractatus 3.313 continues:

In the limiting case the variable becomes a constant, the expression becomes a proposition. (3.313)

The unit of language, Wittgenstein remarks later of his Tractatus, is not the name but the proposition (LWL p119). And the context of this later remark is Tractatus 1.1:

The world is the totality of facts, not of things. (1.1)

The independent, self-standing units of the world are, Wittgenstein asserts, not things but rather the complexes things constitute: facts. Objects do not go together to make something whose reality is, as theirs, dependent, whose nature is, as theirs, a matter of possibilities; the unity that is formed by the copulation together of objects is rather an independent unity, a unity whose nature consists of an actuality. Whilst objects are arrived at in the world only derivatively, by 'looking inside' facts, the facts themselves are come across directly - the facts stand by themselves as independent elements of the totality which is the world. ${ }^{11}$

An analogy, then, of open hands and closed fists: If we take an atomic fact of just two elements, the late Russell will have one of those two (the particular) as a fist (a closed unit) and the second (the universal) as an open hand which may close onto the first to form a complex closed unit; Wittgenstein by contrast will have two open hands which hold each other, close onto each other, to form the complex closed unit which is the fact. ${ }^{12}$

\section{How not to read Tractatus 1.1}

We have arrived through the work above at an understanding of Tractatus 1.1 which is, I take it, nonstandard. It will be useful now to inspect and make contrast with what has been, historically, the most common interpretation of that section. I shall suggest first that that interpretation is intrinsically implausible as an interpretation of Tractatus 1.1; second that it is something Wittgenstein himself rejected as an interpretation of Tractatus 1.1; and third (and most important for this paper) that it is mistaken of the Tractatus as a whole - indeed that its proposal betrays a failure to understand that aspect of the Tractarian metaphysics which Wittgenstein is in fact presenting in Tractatus 1.1.

In his introduction to Wittgenstein’s Tractatus, Russell writes:

The world is not described by merely naming all the objects in it; it is necessary also to know the atomic facts of which these objects are constituents. (TLP pxiv)

This thought is expounded by Sullivan:

Suppose, then, that we take Russell's observation as given: a catalogue of facts, and not merely of things, is needed to distinguish this world from any other, or how things are from how they might have been; in whatever sense that implies, facts belong to the world. (Sullivan $(2005,47)$ )

and has naturally (and I think correctly), been taken as a comment on section 1.1 of Wittgenstein's text. Certainly, Russell's remark has been followed as such. In detailing the world, it is often agreed Wittgenstein asserts in section 1.1, one cannot merely list the things therein - it is required also to say how those things stand there with each other. For if we do not talk also of how things stand, of facts, 
we shall not be able to distinguish this world from a distinct world in which (the same) things stand differently:

At the start we are told that the world is all that is the case: a totality of facts, not merely a totality of things ( 1 and 1.1). The world cannot be identified with a totality of things, since the totality of things can constitute a variety of possible worlds depending upon their arrangement. (Fogelin $(1987,3)$ )

We might imagine a world consisting of objects a and $\mathrm{b}$ and a relation $\mathrm{R}$. If our aim is to describe accurately this world, it is not enough simply to offer a list of these constituents - this list would not distinguish a universe in which aRb is the case from one in which bRa is the case. Instead, our description must incorporate within it some acknowledgement of structure; it must see the world as composed of facts, not things. (Ostrow $(2002,23)$ )

But we can and should, I think, be immediately suspicious of such interpretations. For central to their offering is a use of the word 'merely', 'just', 'simply' etc.: In giving the world one must catalogue not just the things therein but also the facts there constituted by those things. ${ }^{13}$ Wittgenstein, however, did not write at Tractatus 1.1 that the world is the totality not merely of things but also of facts, that the world is composed variously of things and also of facts constituted by those things: he wrote that the world is the totality of facts, and not of things - not of things at all.

Further, there is textual evidence to suggest that Wittgenstein himself rejected such an interpretation of the Tractatus' opening passage. In conversation with Desmond Lee during the year 1930-1931, Wittgenstein is recorded as saying of his earlier work:

1. "The world is everything that is the case". This is intended to recall and correct the statement "The world is everything that there is"; the world does not consist of a catalogue of things and facts about them (like the catalogue of a show). (LWL p119)

The world does not consist of a catalogue simply of things; nor indeed, Wittgenstein retrospectively adds, does it consist of a catalogue of things and also of facts about them (facts of which they are constituents $)^{14}$. This addition seems very likely to have been provoked by and directed at Russell's comment in the introduction to his book.

More than voicing suspicions of the Russellian rendering of Tractatus 1.1 as a rendering of Tractatus 1.1, however, we are in a position to find it misguided as a comment on the Tractatus more generally. For what is seen by its advocates is (I take it) a world constituted both of simples (the objects) and also of complexes composed of those simples (the facts): and Wittgenstein as being keen to point out that the complexes must be included too. ${ }^{15,16}$ So to envision the world, however, is to fail to notice that what is simple in the Tractatus - an object - is not, as what is complex, any kind of self-standing unit.

We do not come across equally in the world both simples and complexes; rather, what we come across in the first instance are only complexes, simples being found only subsequently by (as it were) 'looking inside' the complexes. ${ }^{17}$ To think of the world as consisting variously of both objects and facts is to be involved in a failure to recognise this contrast and subordination. Properly taking on board what Wittgenstein in fact intends by Tractatus 1.1 should leave no inclination whatsoever to say: the world is not the totality merely of things.

\section{Notes}

${ }^{1}$ It has, incorrectly to my mind, been denied that atomic facts (Sachverhalten) are what the Tractatus talks of as complexes (Komplexen) (see, e.g., Hacker $(1989,115))$. Whilst Wittgenstein may not have been explicit with the identification in the Tractatus itself, he was so explicit in retrospect (see BB p31 and the unpublished Typescript 220 (called 'Proto-Philosophical Investigations') §108). Here is not space, however, to argue the point. What Wittgenstein does say in the Tractatus of an atomic fact is that it is a combination (eine Verbindung) of objects, that it is composed (zusammengesetzt) of objects 
(4.2211), and that it has objects as its constituents (Bestandteile) (2.011). (Komplexen, in the same terms, are said to be composed of constituent objects (2.0201, 2.021, 4.441).) I shall express this idea with the words: an atomic fact is a complex of objects. Whether or not this use of the noun 'complex' goes against that of the Tractatus should not be felt to be of importance.

${ }^{2}$ See, e.g., RA p135

${ }^{3}$ To respond that one of the constituents, one of the bricks, can be turned into cement and then used to bond the others together would be to misunderstand. Taking the complex apart, what was cement at once solidifies into a brick - and it is as a brick that it must stay, just so long as it is something apart from other things. In itself, the cement is not cement at all but a brick. Another approach to Russell's difficulty here is to find that if the cement must be thought of as being, at the same time, a brick, then the question seems possible: what holds the cement-brick to the other bricks?, and a Bradleian regress is threatened. Further exploration of Russell's difficulty is not, however, possible in this chapter. (See Linsky (1992) for a more detailed examination.)

${ }^{4}$ Forms are required in 1913 to stand as terms of judgment relations in order to address a problem of unity in thought (see TK p116). More, forms must, just as everything else, be terms. To deny of anything that it is a term is self contradictory, for what can be made the subject of a proposition (what can be talked/thought about) must already be a term. (See POM p43; OF pp. 98, 99.)

${ }^{5}$ Russell had not of course begun on Theory of Knowledge by January 1913. He had already by that time, however, developed the idea exposed in that text that a complex contains something - a form beside its constituent terms and relation. In October 1912 he writes: "In a complex, there must be something, which we may call the form, which is not a constituent, but the way the constituents are put together" (WL p55).

${ }^{6}$ See, e.g., POM p43.

${ }^{7}$ See Frege $(1997,193)$ : "For not all parts of a thought can be complete; at least one must be unsaturated or predicative; otherwise they would not hold together.” I focus on Russell rather than Frege with the question of unity because the concern in both Russell and Wittgenstein is with the unity of complexes operating at the level of reference (complexes of objects of reference). The wholes and parts which Frege deals with arise, by contrast, at the level of sense - the senses of the elements of a proposition go together to form a thought. Of course, Frege does talk of (un)saturation at the level of reference, writing: "A concept is unsaturated in that it requires something to fall under it; hence it cannot exist on its own" (Frege $(1997,81)$ ), but as it is not the case that when an object falls under a concept there is some unity of concept-and-object there constructed it is slightly mysterious what that talk might there mean. This he seems himself to acknowledge: “The words 'unsaturated' and 'predicative' seem more suited to the sense than the referent; still there must be something on the part of the referent which corresponds to this, and I know of no better words" (Frege (1997,174 footnote).

${ }^{8}$ Compare POM p44: "No proposition contains less that two constituents".

${ }^{9}$ See Ramsey’s paper Universals in Ramsey (1990, 8-33) (especially p11 and pp.17-18) for an understanding of Wittgenstein's objects in agreement with that of this paper. More recently, Linsky has written: "All of the constituents of the proposition in the Tractatus are incomplete" (Linsky 1992, 266-267), and Proops briefly considers the idea "that the reference of every name is, as Frege would say, 'in need of saturation,' so that each object plays an equal role in securing the unity of the atomic state of affairs in which it occurs” (Proops 2004, §1). I am unaware, however, of further examples of Tractarian objects being described, or clearly thought of, as incomplete in the way of a late Russellian universal, or of a sense of a Fregean concept word. Argumentation in this area has been focused instead on whether objects include properties and relations as well as particulars - a debate which I consider to be misconceived (Wittgenstein does not take the Russellian categories of particular, property and relation to be a priori applicable, see note 10 below). Anscombe asserts it "fairly clear" that Ramsey was mistaken (Anscombe $(1971,99)$ ). See the third section of this paper for further authors lined up, implicitly, against the conclusions of this second.

${ }^{10}$ It is perhaps worth indicating here how I take it that one should respond to the (common) question of the number of objects contained in the fact corresponding to the proposition whose sign is 'aRb' as discussed in Tractatus 3.1432 - is it three, or just two?

Instead of, 'The complex sign " $a R b$ ” says that $a$ stands to $b$ in the relation $R$, we ought

to put, "That " $a$ " stands to " $b$ " in a certain relation says that $a R b$. (3.1432)

The inquiry is, I think, misconceived. What we have to remember here is that this section is pulled straight from the 1913 Notes on Logic (NB p106), and further that in 1913 Wittgenstein subscribed to a broadly Russellian concept script with its subject-predicate, dual-relational etc. forms, and going with that to a broadly Russellian metaphysics. This he did not do in the Tractatus. What forms of elementary proposition there are, and so what types (forms) of entity there are, is not, Wittgenstein 
came to think, available in advance of the performance of analysis (available 'a priori') (see, e.g., Tractatus 5.557-5.5571, PO p30, WWK p42). The sign for a (more or less) Russellian dual relational form appearing in section 3.1432 is thus an anachronism, and as such certain concerns surrounding its appearance there - including the 'two or three objects' question - are inappropriate. Of course, this raises the issue what section 3.1432 is about: but the reply here is straightforward. What Wittgenstein is doing in 3.1432 (as through the whole of the 3.14's) is insisting that propositional signs are facts and so fundamentally different in kind from name signs (this is also a key force of the corresponding paragraph in the Notes on Logic). Whilst it may be misleading to press this case in the Tractatus using an outdated example, we should note that despite being outdated, the example has not been replaced there is no alternative concept script given 'a priori' from which to pick a propositional sign to use instead of ' $a R b$ '.

${ }^{11}$ A slight misalignment of this thought with what Wittgenstein actually writes in section 1.1 is his use there of Tatsache (fact) rather than Sachverhalt (atomic fact). In a letter to Russell of 19.8.19 Wittgenstein writes:

"What is the difference between a Tatsache and a Sachverhalt?" Sachverhalt is, what corresponds to an Elementarsatz if it is true. Tatsache is what corresponds to the logical product of elementary props when this product is true. The reason why I introduce Tatsache before introducing Sachverhalt would want a long explanation. (CL p125)

I wish very much that Wittgenstein had nonetheless taken the trouble to give the explanation.

${ }^{12}$ This may not be quite right for Russell: it is not clear in PLA that facts and particulars are 'closed' in the same manner. Russell has taken enough from Wittgenstein by this time to deny that facts are (complex) particulars, but he has no worked out alternative. Perhaps better to run the contrast with Wittgenstein would therefore be Frege: the closed sense of a complex name (e.g. a proposition) may be formed from the open sense of a function word closing onto the closed sense of a proper name. See note 7 above.

${ }^{13}$ See also Kenny (1973, 74): “The world will be, as the Tractatus says, the totality of facts, not things (it is the position, not just the board plus the pieces)”. Sullivan, too, suggests that Russell's idea that: "a catalogue merely of things ... is not enough to fill one centrally important role that philosophy has assigned to the notion of world: the role of what thought answers to, or what thoughts are measured against to be assessed as true or false” (Sullivan $(2005,45)$ ) is at least a part of what Wittgenstein intended in Tractatus 1.1.

${ }^{14}$ The material (external, contingent) properties of an object are precisely the combinations that object enters into with other objects (see 2.0231).

${ }^{15}$ This may be the picture even in recognition that what is simple and what is complex differ in kind, that complexes (facts) are not complex objects, are not complex entities of reference (3.144, 3.24). Russell was by 1918 enough under Wittgenstein's spell to deny that what is complex - a fact - is an entity in the same sense as its simple constituents, but this was not felt as a bar to saying in the same breath that what 'you come across in the world' are both simple things and complex facts composed of those simple things (PLA p270, see also pp. 191-192).

${ }^{16}$ Note how easy it must have been, given his own 'universe' of simples and complexes (see, e.g., PM p44 (above) or RA p134), for Russell to misunderstand Wittgenstein in this way.

${ }^{17}$ Of course, simples have the following species of 'independent reality': they subsist independently of what is the case (2.024) and may be identified as the same across two different complexes (2.0122). (The suggestion is absolutely not that the availability of an object for reference depends upon its occurrence in an existing complex.) But this subsistence is no kind of being in the world, is no kind of presence in the realm of actuality, and that that is so - the dependent nature of objects - is what is ridden roughshod over by the standard interpretation of Tractatus 1.1.

\section{Abbreviations and references}

\section{Works by Russell}

OF: On Functions, in The Collected Papers of Bertrand Russell vol. 4, Urquhart, A. ed, Routledge, New York, 1994, pp. 96-110 
PLA: The Philosophy of Logical Atomism, in Logic and Knowledge, Marsh, R.C. ed, Allen and Unwin, London, 1956, pp. 177-281

PM: Principia Mathematica volume 1, CUP, Cambridge, 1925

POM: The Principles of Mathematics, Routledge, London, 1992

PP: The Problems of Philosophy, OUP, Oxford, 1998

RA: Analytic Realism, in The Collected Papers of Bertrand Russell vol.6, J.G. Slater ed, Routledge, London, 1992, pp. 132-146

RUP: On the Relations of Universals and Particulars, in Logic and Knowledge, R.C. Marsh ed, Allen and Unwin, London, 1956, pp. 105-124

TK: Theory of Knowledge, The Collected Papers of Bertrand Russell vol. 7, E.R. Eames ed, Allen and Unwin, London,1984

WL: What is Logic?, in The Collected Papers of Bertrand Russell vol. 6, J.G. Slater ed, Routledge, London, 1992, pp. 54-56

\section{Works by Wittgenstein}

BB: The Blue and Brown Books, Blackwell, Oxford, 1969

CL: Ludwig Wittgenstein: Cambridge Letters, B. McGuinness and G.H. von Wright eds, Blackwell, Oxford, 1995

LO: Letters to C.K. Ogden, G.H. von Wright ed, Blackwell, Oxford, 1973

LWL: Wittgenstein’s Lectures, Cambridge 1930-1932, D. Lee ed, Blackwell, Oxford, 1980

PO: Philosophical Occasions, J.C. Klagge and A. Nordmann eds, Hackett, Indianapolis, 1993

TLP: Tractatus Logico-Philosophicus, tr. Ogden, Routledge, London, 1922, and tr. Pears and McGuinness; Routledge, London, 1961

WWK: Wittgenstein and the Vienna Circle, B. McGuinness ed, Blackwell, Oxford, 1979

\section{Further references}

Anscombe, G.E.M.: 1971, An Introduction to Wittgenstein’s Tractatus, University of Pennsylvania Press, Philadelphia

Fogelin, R. J.: 1987, Wittgenstein, Routledge, London

Frege, G.: 1997, The Frege Reader, Beaney ed, Blackwell, Oxford

Hacker, P.M.S.: 1989, Insight and Illusion, Thoemmes, Bristol

Kenny, A.: 1973, Wittgenstein, Harvard University Press, Cambridge Mass.

Linsky, L.: 1992, The Unity of the Proposition, Journal of the History of Philosophy 30, pp. 243-273

Ostrow, M. B.: 2002, Wittgenstein’s Tractatus, CUP, Cambridge

Proops, I.: Wittgenstein's Logical Atomism, in E.N. Zalta (ed), The Stanford Encyclopedia of Philosophy (Winter 2004 Edition) URL =

$<$ http://plato.stanford.edu/archives/win2004/entries/wittgenstein-atomism/>. 
Colin Johnston: The Unity of a Tractarian Fact

Ramsey, F. P.: 1990, Philosophical Papers, Mellor ed, CUP, Cambridge

Sullivan, P. M.: 2005, Identity Theories of Truth and the Tractatus, Philosophical Investigations 28 pp. 43-62 